\title{
Influence of ecotourism activities on the forest structure and light intensity in forests of Taman Negara Pahang
}

\begin{abstract}
Ecotourism activities in protected area such as in Taman Negara (i.e., hiking and camping) may result in canopy opening which increases light transmission to the forests floor and influencing the variation in forest structure. Thus, this study was conducted to evaluate the effects of ecotourism activities on the light intensity and examine its influence to the forest structure in the protected forests of Taman Negara Pahang. Information on light intensity and forest stand attributes were collected in a total of $16,20 \mathrm{~m} \times 25 \mathrm{~m}$ plots which consists of camping sites, forest trails and natural areas. All trees Ó $1 \mathrm{~cm}$ in diameter-at-breast height (DBH) were measured, tagged and numbered. The light intensity was measured using hemispherical photography at nine points randomly sampled in each plot. The diffuse light intensity recorded in hemispherical photographs was analysed (in percent) using RGBFisheye software. From the field measurements, there is a significant difference (POे.05) in basal area between two conditions (i.e., disturbed and undisturbed). The means of light intensity as recorded in hemispherical photographs of forest trails, camping sites and natural areas were $11.37 \%, 10.05 \%$ and $8.32 \%$, respectively. Results from the analysis of variance indicated that there was a significant difference in the means of light intensity among study conditions (PÒ.05). Moreover, all study areas showed an inverse J-shaped DBH distribution which indicates the presence of abundance regeneration in the forest and the stands are still at the stage of development. Therefore, the study showed that the increase in light intensity in disturbed areas may result in the variation of forest structure beneath canopy. This could be because of the lesser stratification of canopy layers and the tolerance between some tree species and light in the disturbed areas.
\end{abstract}

Keyword: Ecotourism; Light intensity; Hemispherical photography; Taman Negara Pahang; Camping sites; Forest trails; Natural areas 